\title{
ESTUDO DAS CONDIÇÕES OPERACIONAIS DO HIDROEJETOR
}

\author{
C. C. M. de OLIVEIRA ${ }^{1}$, M. C. GUTIERREZ ${ }^{1}$ e V. SILVEIRA Jr ${ }^{1}$ \\ ${ }^{1}$ Universidade Estadual de Campinas, Departamento de Engenharia de Alimentos \\ E-mail para contato: cintiamelgaco@ hotmail.com
}

\begin{abstract}
RESUMO - A busca por equipamentos simples, acessíveis e de baixo custo é crescente nos processos industriais. Este trabalho teve como objetivo estudar as condições operacionais da água que circula no interior de um hidroejetor. Estudou-se o comportamento do sistema sob alterações da velocidade e temperatura da água de circulação e a possibilidade de cavitação no bocal do hidroejetor. O melhor vácuo obtido foi de $8,5 \mathrm{kPa}$ nas condições operacionais nominais de $4,1 \pm 0,1 \mathrm{~m}^{3} / \mathrm{h}$ e $5 \pm 0,5$ ${ }^{\circ} \mathrm{C}$ da água de circulação. Não houve presença de cavitação no bocal do hidroejetor pois a pressão atingida no mesmo não foi inferior a pressão de saturação da água nas condições operacionais da água de circulação. Portanto, quanto maior a vazão volumétrica e menor a temperatura da água de circulação, maior é a diminuição da pressão no bocal do hidroejetor que pode ser utilizada no processo de resfriamento evaporativo para arrefecimento indireto.
\end{abstract}

\section{INTRODUÇÃO}

O sistema de resfriamento evaporativo é um processo que a natureza oferece em converter calor latente em calor sensível. Uma das formas de ocorrer o resfriamento evaporativo acontece quando o sistema é submetido a baixas pressões, ou seja, a pressão de vapor da água na fase líquida, que é a pressão de saturação, quando superior à pressão de vapor parcial da água na fase de gasosa permite-se a evaporação. Para isso, a água na fase líquida absorve calor da sua vizinhança, aumenta a sua energia interna e muda de estado de agregação, passando para a fase vapor, enquanto a água restante no recipiente se resfria. Este sistema está sendo bastante utilizado para climatização de ambiente para conforto térmico humano, confinamento de animais, em estufas, no armazenamento de produtos hortifrutigranjeiros, torre de resfriamento de água, lavadores de ar, condensadores evaporativos, etc. Segundo Schibuola (1997) o sistema pode ser utilizado como pré-resfriador no sistema convencional, reduzindo, portanto os custos de operação do sistema.

$\mathrm{Na}$ construção do sistema de resfriamento evaporativo, utilizando baixas pressões, é preciso operar equipamentos que o produza, retirando as moléculas do recipiente, a fim de reduzir a massa específica molecular e, portanto, a pressão, com o uso de bomba de vácuo ou ejetores. Ejetores, dito também como trompas, são dispositivos que constam essencialmente de um tubo aspirador e um bocal convergente alimentando um bocal convergente-divergente.

Para sistemas de resfriamento evaporativo com uso de ejetores têm-se disponíveis ejetores a vapor e ejetores com uso de líquido como fluido de circulação no seu interior, sendo equipamentos 
regidos pelo princípio de Bernoulli, onde a ocorrência de baixas pressões se dá pela simples diminuição do diâmetro da "garganta", mas que, por sua vez, possui baixo coeficiente de desempenho devido ao baixo vácuo alcançado. O fluido escolhido para percorrer o interior do ejetor foi a água, identificada como água de circulação. A escolha do fluido se deu devido ao local escolhido para aplicação do sistema de resfriamento evaporativo e aos recursos disponíveis, local com abundância de circulação de água, além de eliminar a inconveniência de torna-se dependente de caldeiras ou outra fonte de energia para obtenção de vapores d'água.

Aphornratana e Eames (1997) relatam que quando comparado um sistema de refrigeração por absorção com um sistema de refrigeração por ejetor e uso de vapor, este último é relativamente simples de construir, operar e controlar, usando apenas um componente de fluido de trabalho. E mesmo que o coeficiente de desempenho (COP) seja relativamente baixo (menor que 0,3 no presente estudo), o seu custo de capital e de manutenção deverão fazê-lo tornar-se um sério concorrente com qualquer outro ciclo.

Assim, o objetivo deste trabalho foi avaliar as condições operacionais, velocidade e temperatura da água de circulação e também o comportamento do sistema perante a possibilidade de ocorrência de cavitação em hidroejetores.

\section{MATERIAL E MÉTODOS}

O sistema de resfriamento evaporativo ensaiado consiste nos seguintes equipamentos: um reservatório de água para resfriamento a baixa pressão, também podendo ser utilizado para termoacumulação; reservatório de água para circulação (volume de $80 \mathrm{~L}$ ); bomba centrífuga (marca Thebe e modelo Th 16), que faz a circulação da água armazenada no reservatório de circulação até o hidroejetor; hidroejetor, composto com dois compartimentos (convergente e divergente), conforme mostra a Figura 1; banho termostático para resfriamento indireto da água de circulação e mangueira de vácuo para conexão do bocal do hidroejetor ao reservatório de resfriamento.

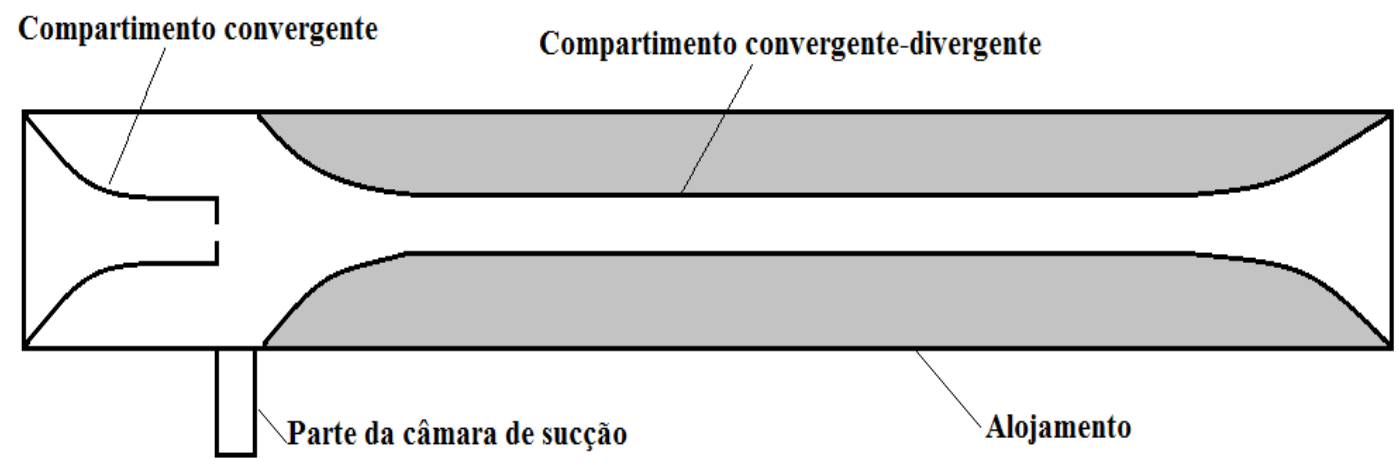

Figura 1 - Esquema do Hidroejetor. 
A instrumentação instalada para avaliação das condições operacionais ensaiadas é mostrada na Figura 2.

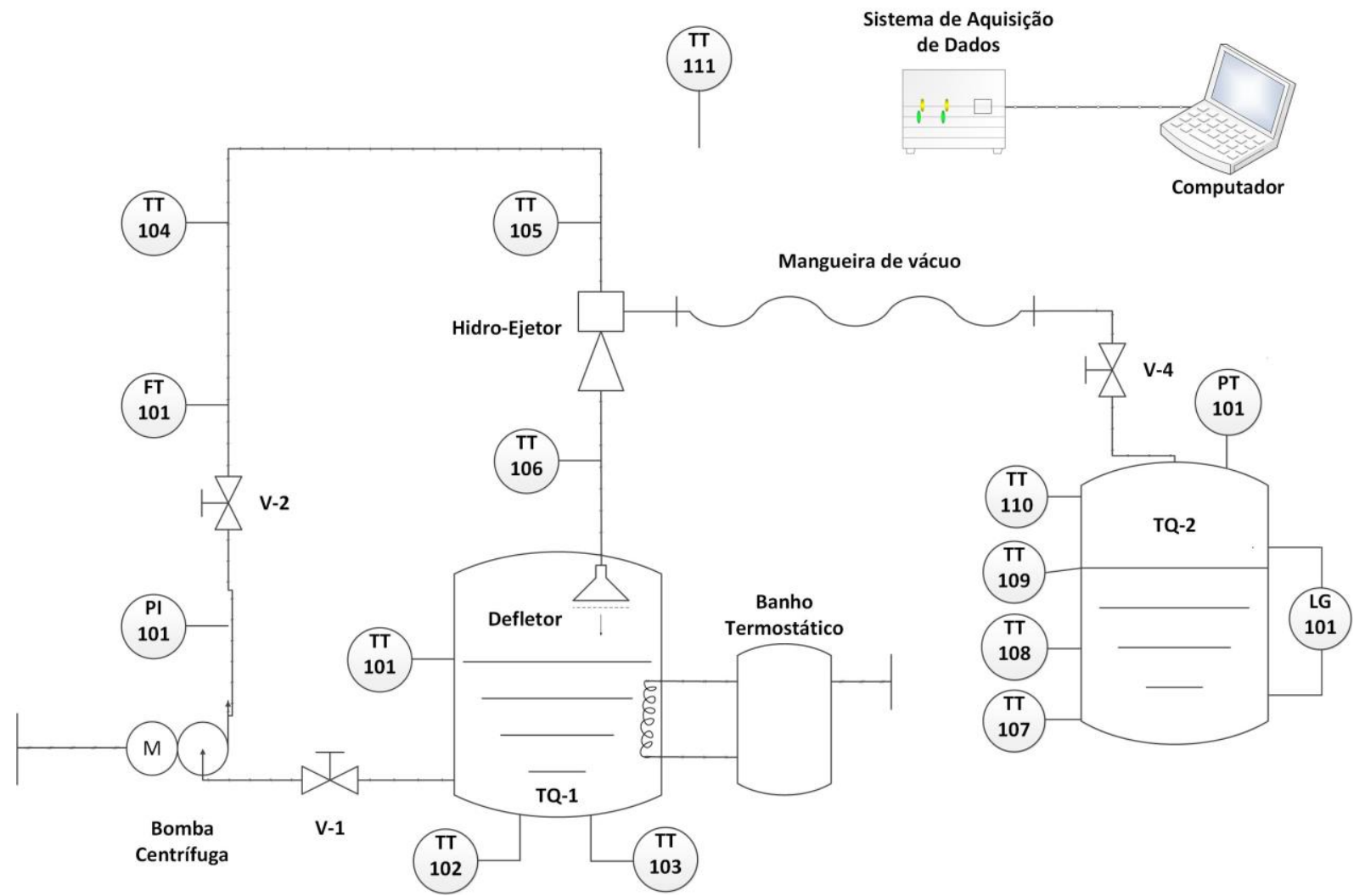

Figura 2 - Esquema instrumental do sistema de resfriamento evaporativo utilizando hidroejetor.

A descrição da montagem e instrumentação são: TQ-1, Reservatório de circulação; TQ-2, Reservatório de resfriamento; V-1, Válvula esfera na saída do reservatório de circulação; V-2, Válvula agulha após a bomba centrífuga; V-4, Válvula esfera no reservatório de resfriamento; TT 101, Transdutor de temperatura no reservatório de circulação 01; TT 102, Transdutor de temperatura no reservatório de circulação 02; TT 103; Transdutor de temperatura no reservatório de circulação 03; TT 104, Transdutor de temperatura depois da bomba centrífuga; TT 105, Transdutor de temperatura antes do hidroejetor; TT 106, Transdutor de temperatura depois do hidroejetor; TT 107, Transdutor de temperatura no reservatório de resfriamento 01; TT 108, Transdutor de temperatura no reservatório de resfriamento 02; TT 109, Transdutor de temperatura no reservatório de resfriamento 03; TT 110, Transdutor de temperatura no reservatório de resfriamento 04; TT 111, Transdutor de temperatura no ambiente; PT 101 e PI 101, Transmissor de pressão e Indicador de pressão (Manômetro) e FT 101, Transmissor de vazão.

O sistema foi instrumentado com sensores de pressão (modelo TPI-Press e série 78703); sensores de temperatura (termorresistências do tipo Pt100), com precisão de $0,2{ }^{\circ} \mathrm{C}$ e linearidade $\left(\mathrm{R}^{2}=0,99\right)$ e medidor e transmissor de vazão tipo magnético. Os dados foram registrados pelo programa Field Chart 1.76 em intervalos de 30 segundos. 
De acordo com a configuração do hidroejetor, o mesmo fornece uma queda de pressão quando o fluido percorre o compartimento convergente, onde há o aumento da velocidade e redução da pressão. Como o bocal está conectado ao reservatório de resfriamento pela câmara de sucção, então há a redução da pressão no reservatório de resfriamento. A princípio, ocorre a sucção de ar úmido do reservatório de resfriamento, o que permite que a pressão parcial da água na fase gasosa presente no reservatório de resfriamento seja reduzida, ficando abaixo da pressão de saturação da água líquida. Esse fenômeno leva a evaporação da água presente no reservatório de resfriamento, que pelo processo de transferência de massa e calor provoca o resfriamento da água de resfriamento. Esse ar úmido ou vapor de água a baixa pressão são succionados juntamente do reservatório de resfriamento pela água de circulação e se misturam na câmara de mistura do hidroejetor. Neste local, recuperam a pressão de forma suficiente para equilibrar a pressão atmosférica no difusor divergente, pelo aumento do diâmetro do mesmo, e alcançam o reservatório de circulação.

Os ensaios consistiram em avaliar os efeitos sobre a temperatura da água de resfriamento sob as variações das condições operacionais e possibilidade de ocorrência de cavitação no bocal do hidroejetor:

\subsection{Condições operacionais}

Os efeitos das variáveis operacionais, potencialmente influenciáveis, a temperatura da água de circulação e a velocidade na secção convergente que esta água passava no bocal do hidroejetor, por meio da vazão volumétrica fornecida pela bomba centrífuga, foram avaliados quanto ao nível de vácuo atingido e sua consequente estabilização da temperatura do fluido no reservatório de resfriamento. As temperaturas estudadas para água de circulação foram: 5, 10, 15, 20 e $25 \pm 0,5$ ${ }^{\circ} \mathrm{C}$, obtidas pelo sistema de resfriamento instalado no reservatório de circulação (banho termostático e trocador de calor de forma espiral de cobre) ou com complementação de uma quantidade de gelo. As vazões volumétricas foram definidas tendo como referência a pressão com que a água armazenada no reservatório de resfriamento começava a resfriar. Sendo assim as vazões volumétricas nominais estudadas foram 3,$7 ; 3,9$ e $4,1 \pm 0,1 \mathrm{~m}^{3} / \mathrm{h}$, originando as respectivas velocidades no bocal do hidroejetor 19,$5 ; 20,5$ e $21,5 \mathrm{~m} / \mathrm{s}$, as quais foram moduladas pela válvula agulha e registradas pelo medidor de vazão magnético.

\subsection{Cavitação}

Outro fato analisado no sistema foi a possibilidade de cavitação no bocal do hidroejetor e o quanto isto prejudicaria a vácuo atingido no reservatório de resfriamento (TQ-2). A cavitação poderia ocorrer devido à redução de pressão no bocal do hidroejetor podendo alcançar uma pressão menor que a pressão de saturação da água de circulação na temperatura em que a mesma se encontrava.

A existência da cavitação foi verificada visualmente através do material translúcido que compôs o hidroejetor, vidro, no momento em que a água de circulação passava no bocal do mesmo e pelo acompanhamento do comportamento da queda de pressão no reservatório de resfriamento (TQ-2), através da instrumentação nele instalado. 


\section{RESULTADOS E DISCUSSÃO}

\subsection{Velocidade e temperatura da água de circulação}

Para que ocorra o resfriamento do líquido a baixa pressão, além de um projeto adequado dos compartimentos que compõem o hidroejetor, tem-se combinado a ele a temperatura e a velocidade da água de circulação. Segundo Jeong et al. (2005) a diminuição gradativa da temperatura da água de circulação tem o intuito de diminuir a pressão no ejetor, pois, em geral, a densidade da água depende da temperatura. Em relação a velocidade da água de circulação, a mesma tem influência sobre a pressão no bocal do hidroejetor, visto que o hidroejetor é regido pelo princípio de BERNOULLI. Para manter constante a energia mecânica no compartimento convergente, o aumento da energia cinética do fluido, proporciona uma diminuição da energia de pressão no bocal, considerando desprezível a variação da energia potencial, pois a diferença da distância entre os dois pontos no volume de controle escolhido foi muito pequena. $\mathrm{O}$ sistema foi submetido às vazões volumétricas nominais de 3,$7 ; 3,9$ e $4,1 \pm 0,1 \mathrm{~m}^{3} / \mathrm{h}$ e as temperaturas nominais de $5,10,15$, 20 e $25 \pm 0,5^{\circ} \mathrm{C}$ em cada vazão estudada.

Em todos ensaios experimentais realizados, foi observado que quanto menor a temperatura da água de circulação, na mesma vazão volumétrica nominal estudada, menor foi à temperatura da água armazenada no reservatório de resfriamento atingida, pois menor foi à pressão alcançada da água de circulação na mesma temperatura, devido ao aumento da velocidade no bocal do hidroejetor que gerou uma maior diminuição da pressão. Na Figura 3, mostra a condição de pressão obtida em três condições de vazões volumétricas estudadas e nas cinco diferentes temperaturas da água de circulação.

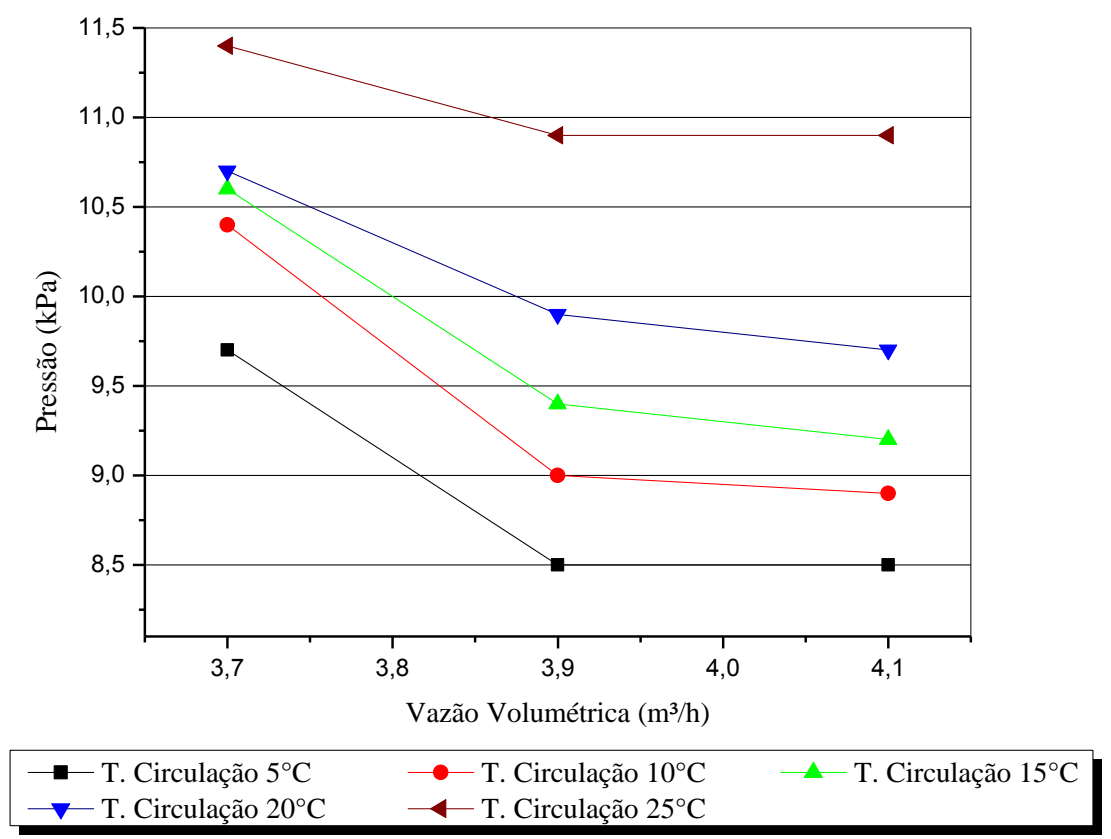

Figura 3 - Comportamento da pressão em diferentes temperaturas nominais da água de circulação nas vazões nominais de 3,$7 ; 3,9$ e $4,1 \pm 0,1 \mathrm{~m}^{3} / \mathrm{h}$. 
Os resultados das temperaturas alcançadas pela água de resfriamento nas diferentes combinações da vazão volumétrica nominal e temperatura nominal da água de circulação, são encontrados na Tabela 1 .

Tabela 1 - Temperatura atingida pela água de resfriamento $\left({ }^{\circ} \mathrm{C}\right)$, contida no reservatório de resfriamento, nas diferentes condições operacionais nominais, sem aplicação de carga térmica e na temperatura média inicial de $30{ }^{\circ} \mathrm{C}$

\begin{tabular}{cccccc}
\hline Vazão volumétrica nominal & \multicolumn{5}{l}{ Temperatura Nominal da Água de Circulação $\left( \pm 0,5^{\circ} \mathrm{C}\right)$} \\
\cline { 2 - 6 } água de circulação $( \pm 0,1)$ & $5{ }^{\circ} \mathrm{C}$ & $10{ }^{\circ} \mathrm{C}$ & $15{ }^{\circ} \mathrm{C}$ & $20{ }^{\circ} \mathrm{C}$ & $25{ }^{\circ} \mathrm{C}$ \\
\hline $3,7 \mathrm{~m}^{3} / \mathrm{h}$ & 20,4 & 22,3 & 23,5 & 24,5 & 27,9 \\
$3,9 \mathrm{~m}^{3} / \mathrm{h}$ & 10,5 & 13,6 & 16,6 & 21,4 & 25,9 \\
$4,1 \mathrm{~m}^{3} / \mathrm{h}$ & 9,7 & 12,7 & 16,3 & 21,4 & 26,2 \\
\hline
\end{tabular}

As temperaturas atingidas pela água de resfriamento na vazão volumétrica nominal de $3,7 \pm$ $0,1 \mathrm{~m} / \mathrm{h}$ foram bem maiores que as temperaturas da água de resfriamento atingidas nas vazões volumétricas nominais de $3,9 \pm 0,1 \mathrm{~m}^{3} / \mathrm{h}$ e $4,1 \pm 0,1 \mathrm{~m}^{3} / \mathrm{h}$, na mesma temperatura da água de circulação. O mesmo não ocorreu entre as vazões volumétricas nominais de $3,9 \pm 0,1 \mathrm{~m} / \mathrm{h}$ e $4,1 \pm$ $0,1 \mathrm{~m}^{3} / \mathrm{h}$, onde as temperaturas atingidas da água de resfriamento foram próximas, quando submetido à mesma temperatura de circulação, diferindo em menos de $1{ }^{\circ} \mathrm{C}$. Esta pequena variação pode ter acontecido devido a variação da vazão volumétrica nominal de $3,9 \pm 0,1 \mathrm{~m}^{3} / \mathrm{h}$ em cada temperatura da água de circulação se aproximar da vazão volumétrica nominal de $4,1 \pm$ $0,1 \mathrm{~m} / \mathrm{h}$ nas respectivas temperaturas da água de circulação.

Considerando que a temperatura inicial da água de resfriamento estava em cerca de $30^{\circ} \mathrm{C}$, quando o sistema era submetido a temperatura nominal de $5 \pm 0,5{ }^{\circ} \mathrm{C}$ e na vazão volumétrica nominal $3,7 \pm 0,1 \mathrm{~m}^{3} / \mathrm{h}$ conseguiu resfriar a água de resfriamento em torno de um $\Delta \mathrm{T}=10{ }^{\circ} \mathrm{C}$, enquanto nas vazões volumétricas nominais de $3,9 \pm 0,1 \mathrm{~m}^{3} / \mathrm{h}$ e $4,1 \pm 0,1 \mathrm{~m}^{3} / \mathrm{h}$, este $\Delta \mathrm{T}$ médio foi em torno de $20^{\circ} \mathrm{C}$. A medida que a temperatura da água de circulação aumentou, a diferença de temperatura inicial e final da água de resfriamento diminuiu. Portanto a mesma tendência foi obtida quando comparado ao trabalho de Jeong et al. (2005). Eles demonstraram que a pressão cai acentuadamente quanto maior a vazão que passa pelo bico do ejetor e que a queda de pressão é maior quanto menor a temperatura do fluido no mesmo, visto que a massa específica da água depende da temperatura. 


\subsection{Estudo da cavitação no bocal do hidroejetor}

Um dos eventos observado no hidroejetor foi a possibilidade de formação de bolhas de vapor em seu bocal decorrente da acentuada queda de pressão e como isso interferiria no vácuo presente no reservatório de resfriamento (TQ-2). Esse fenômeno é conhecido como cavitação, formação de cavidades dentro da massa líquida.

De acordo com o princípio de Bernoulli, quando a água de circulação escoa no bocal do hidroejetor, o fluido é acelerado por causa da redução do diâmetro. Para manter a energia mecânica constante no compartimento convergente, ocorre uma redução na pressão, podendo esta alcançar um valor menor que a pressão de saturação da água de circulação na temperatura em que ela se encontra. Portanto, haveria formação de bolhas de vapor no bocal do hidroejetor. Após essas bolhas forem carregadas para uma região, câmara de mistura e difusor divergente do hidroejetor, em que a pressão fosse superior a pressão de saturação do fluido, ocorreriam "implosões" das mesmas ocasionando fissuras no equipamento, caso ocorra perto da superfície, pela liberação sucessiva de ondas de choques e micro jatos, altamente energéticos. A Figura 4 mostra a pressão de saturação e a pressão que o reservatório de resfriamento alcançou, nas diferentes condições operacionais nominais.

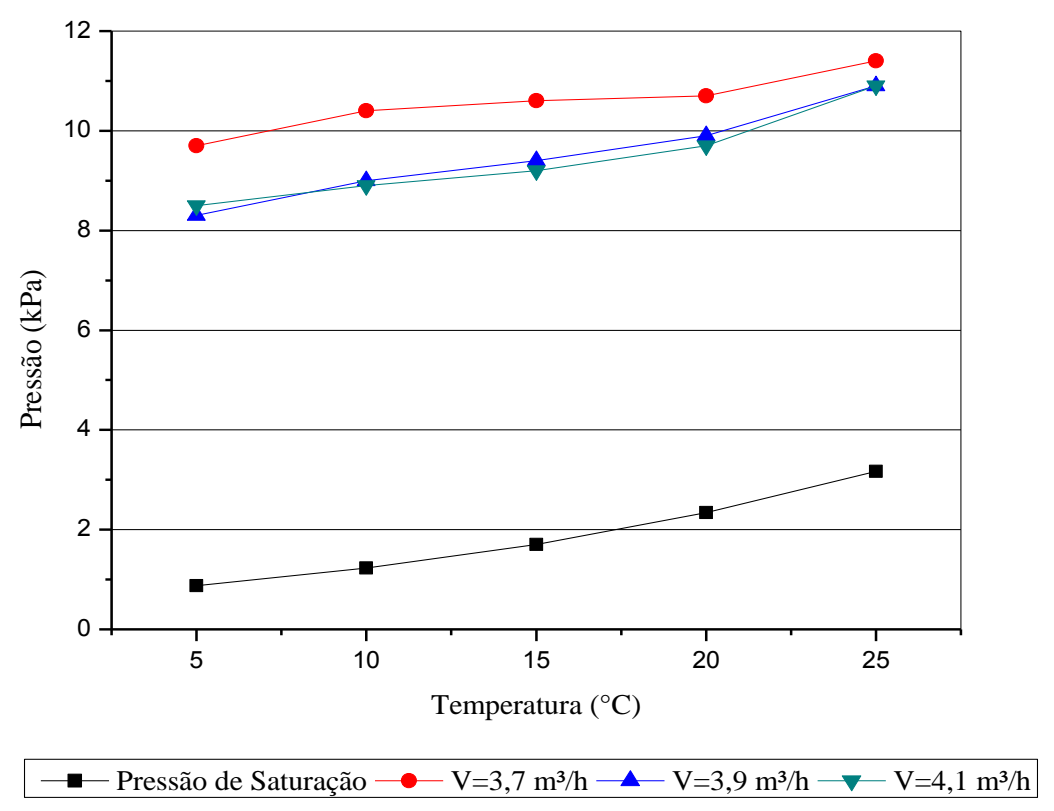

Figura 4 - Comparação da pressão de saturação da água de circulação em relação a pressão atingida pela mesma no sistema de resfriamento evaporativo, nas diferentes combinações das condições operacionais nominais.

De acordo com os resultados apresentados, observou-se que a pressão atingida pela água de circulação no bocal do hidroejetor foi superior à pressão de saturação da água de circulação em todas as condições operacionais imposta ao sistema, portanto não ocorreu possibilidade de 
cavitação durante o funcionamento do sistema.

\section{CONCLUSÕES}

Entre as diferentes condições operacionais imposta ao sistema de resfriamento evaporativo com uso de hidroejetor pode-se observar que quanto maior a vazão volumétrica e menor a temperatura da água de circulação, obter-se-á uma menor pressão na câmara de sucção. Dependendo do vácuo atingido, a pressão de vapor da água na fase gasosa quando menor que a pressão de saturação da água, ocorre o resfriamento da água armazenada no reservatório de resfriamento (TQ-2), sendo intensificado quanto menor for a pressão. No sistema em estudo, a maior queda de temperatura da água de resfriamento ocorreu nas condições operacionais com a vazão volumétrica nominal de $4,1 \pm 0,1 \mathrm{~m}^{3} / \mathrm{h}$ e na temperatura nominal de $5 \pm 0,5^{\circ} \mathrm{C}$ da água de circulação, resultando na temperatura média final de aproximadamente $9{ }^{\circ} \mathrm{C}$ da água de resfriamento armazenada no reservatório de resfriamento (TQ-2).

As condições operacionais nominais impostas ao sistema de resfriamento em estudo não permitiu que o sistema alcançasse uma pressão menor que a pressão de saturação da água de circulação, logo não houve a presença de cavitação. Portanto a queda acentuada da pressão no bocal do hidroejetor não foi prejudicial na diminuição da pressão e consequentemente no resfriamento da água armazenada no reservatório de resfriamento (TQ-2).

AGRADECIMENTO

À Capes

\section{REFERÊNCIAS}

APHORNRATANA, S.; EAMES, I. W. A small capacity steam-ejector refrigerator: experimental investigation of a system using ejector with movable primary nozzle. Int. J. Refrig. - Revue Internationale Du Froid, 20, 352-358, 1997.

JEONG, H. M.; CHUNG, H. S.; BAE, K. Y.; KIM, S. H.; SHIN, Y. S. Water cooling characteristics in an enclosed vacuum tank by water driven ejector. J. Mech Sci Technol, 19, 164-172, 2005.

SCHIBUOLA, L. High-efficiency recovery for air-conditioning applications in a mild climate: A case study. Appl Therm Eng, 17, 447-454, 1997. 